\title{
Scapular and rotator cuff muscle activity during arm elevation: A review of normal function and alterations with shoulder impingement
}

\author{
Atividade dos músculos escapulares e do manguito rotator durante a \\ elevação do braço: Uma revisão da função normal e das alterações na \\ síndrome do impacto
}

Phadke V', Camargo PR², Ludewig PM³

\begin{abstract}
Objective: The purpose of this manuscript is to review current knowledge of how muscle activation and force production contribute to shoulder kinematics in healthy subjects and persons with shoulder impingement. Results: The middle and lower serratus anterior muscles produce scapular upward rotation, posterior tilting, and external rotation. Upper trapezius produces clavicular elevation and retraction. The middle trapezius is primarily a medial stabilizer of the scapula. The lower trapezius assists in medial stabilization and upward rotation of the scapula. The pectoralis minor is aligned to resist normal rotations of the scapula during arm elevation. The rotator cuff is critical to stabilization and prevention of excess superior translation of the humeral head, as well as production of glenohumeral external rotation during arm elevation. Alterations in activation amplitude or timing have been identified across various investigations of subjects with shoulder impingement as compared to healthy controls. These include decreased activation of the middle or lower serratus anterior and rotator cuff, delayed activation of middle and lower trapezius, and increased activation of the upper trapezius and middle deltoid in impingement subjects. In addition, subjects with a short resting length of the pectoralis minor exhibit altered scapular kinematic patterns similar to those found in persons with shoulder impingement. Conclusion: These normal muscle functional capabilities and alterations in patient populations should be considered when planning exercise approaches for the rehabilitation of these patients.
\end{abstract}

Key-words: electromyography; muscle activation; scapula; shoulder pain

\section{Resumo}

Objetivo: O objetivo deste manuscrito é revisar o conhecimento atual sobre como a ativação muscular e a produção de força contribuem para a cinemática do ombro em indivíduos saudáveis e em pessoas com síndrome do impacto. Resultados: As porções média e inferior do músculo serrátil anterior produzem rotação para cima, inclinação posterior e rotação externa na escápula. O trapézio superior produz elevação e retração da clavícula. O trapézio médio é principalmente um estabilizador medial da escápula. O trapézio inferior auxilia na estabilização medial e rotação para cima da escápula. O músculo peitoral menor está alinhado para resistir às rotações normais da escápula durante a elevação do braço. O manguito rotador é crucial para a estabilização e prevenção do excesso de translação superior da cabeça do úmero, assim como para a produção de rotação externa na glenoumeral durante a elevação do braço. Foram identificadas alterações na amplitude ou no tempo de ativação em diversas investigações que compararam sujeitos portadores de síndrome do impacto com controles saudáveis. As alterações incluem ativação reduzida do músculo serrátil anterior médio ou inferior e do manguito rotador, ativação retardada do trapézio médio e inferior, assim como maior ativação do trapézio superior e do deltóide médio em sujeitos com síndrome do impacto. Além disso, sujeitos com o músculo peitoral menor com curto comprimento de repouso apresentam padrões alterados de cinemática escapular semelhantes aos encontrados em pessoas com síndrome do impacto. Conclusão: Estas capacidades musculares funcionais normais e alterações nas populações de pacientes devem ser consideradas no planejamento de programas de exercícios para a reabilitação destes pacientes.

Palavras-chave: eletromiografia; ativação muscular; escápula; dor no ombro. 


\section{Introduction $: \because$.}

Shoulder "impingement" was described by Neer in $1972^{1}$. Shoulder impingement is one of the most common conditions that affect the shoulder and accounts for $44-65 \%$ of all cases of shoulder pain ${ }^{2}$. Impingement usually refers to compression and mechanical abrasion of the rotator cuff tendons, subacromial bursae, or long head of the biceps tendon beneath the anterior undersurface of the acromion, coracoacromial ligament, or undersurface of the acromioclavicular joint during elevation of the $\mathrm{arm}^{1}$. Another possible mechanism of impingement can be attributed to intrinsic breakdown of the rotator cuff tendons as a result of tension overload ${ }^{3}$. Recently, an additional classification of impingement known as internal impingement has been identified ${ }^{4}$. Internal impingement is believed caused by friction and mechanical abrasion of the undersurface of the rotator cuff tendons against the anterior or posterior glenoid rim or glenoid labrum 5 . Internal impingement was first identified as posterior internal impingement in throwers during abduction and external rotation of the humerus relative to the scapula ${ }^{4,6}$.

Several investigators ${ }^{7-13}$ have studied 3-D (3-dimensional) shoulder kinematics during arm elevation, including how abnormal motion may relate to shoulder impingement. It has been described that during elevation of the arm in healthy subjects the scapula should upwardly rotate and posteriorly tilt $^{14,15}$ (Figure 1). Scapular internal or external rotation is more variable on the thorax depending on the plane of elevation and portion of the range of motion ${ }^{14-17}$. It is generally accepted that end range humeral elevation will include scapular external rotation, although limited data is available..$^{15}$ Typically little change in scapular internal rotation will occur during elevation in the plane of the scapula (approximately 40 degrees anterior to the frontal plane) $)^{15-17}$. Position and control of the scapula on the thorax play a critical role in normal function of the shoulder. Stabilization is provided through the scapulothoracic musculature by approximating or compressing the scapula to the thorax. Scapular motions on the thorax align the glenoid fossa with the humeral head maximizing joint congruency and providing a stable base for humeral motion ${ }^{18}$. Scapulothoracic motion results from combined acromioclavicular (AC) and sternoclavicular (SC) joint motions ${ }^{17,19,20}$. During arm elevation in healthy subjects, the clavicle should elevate slightly, retract, and posteriorly rotate at the SC joint ${ }^{19,21,22}$, while the humerus should elevate and externally rotate ${ }^{11,17,23}$. Upward rotation, internal rotation, and posterior tilting of the scapula occur at the AC joint during arm elevation ${ }^{1720,22}$. Normal kinematics of the shoulder are believed critical to preserving the subacromial space and preventing impingement during arm elevation. The length-tension relationship and load of the rotator cuff and scapular muscles and tendons are also believed to be influenced by normal kinematics.

Alterations in this normal motion of the shoulder have been associated with shoulder pathologies such as shoulder impingement $t^{7-9,11-13,24-26}$. Studies have demonstrated that subjects with shoulder impingement may present with decreased scapular upward rotation and posterior tilt, and increased scapular internal rotation during arm elevation ${ }^{7-9,24,26}$. Increased

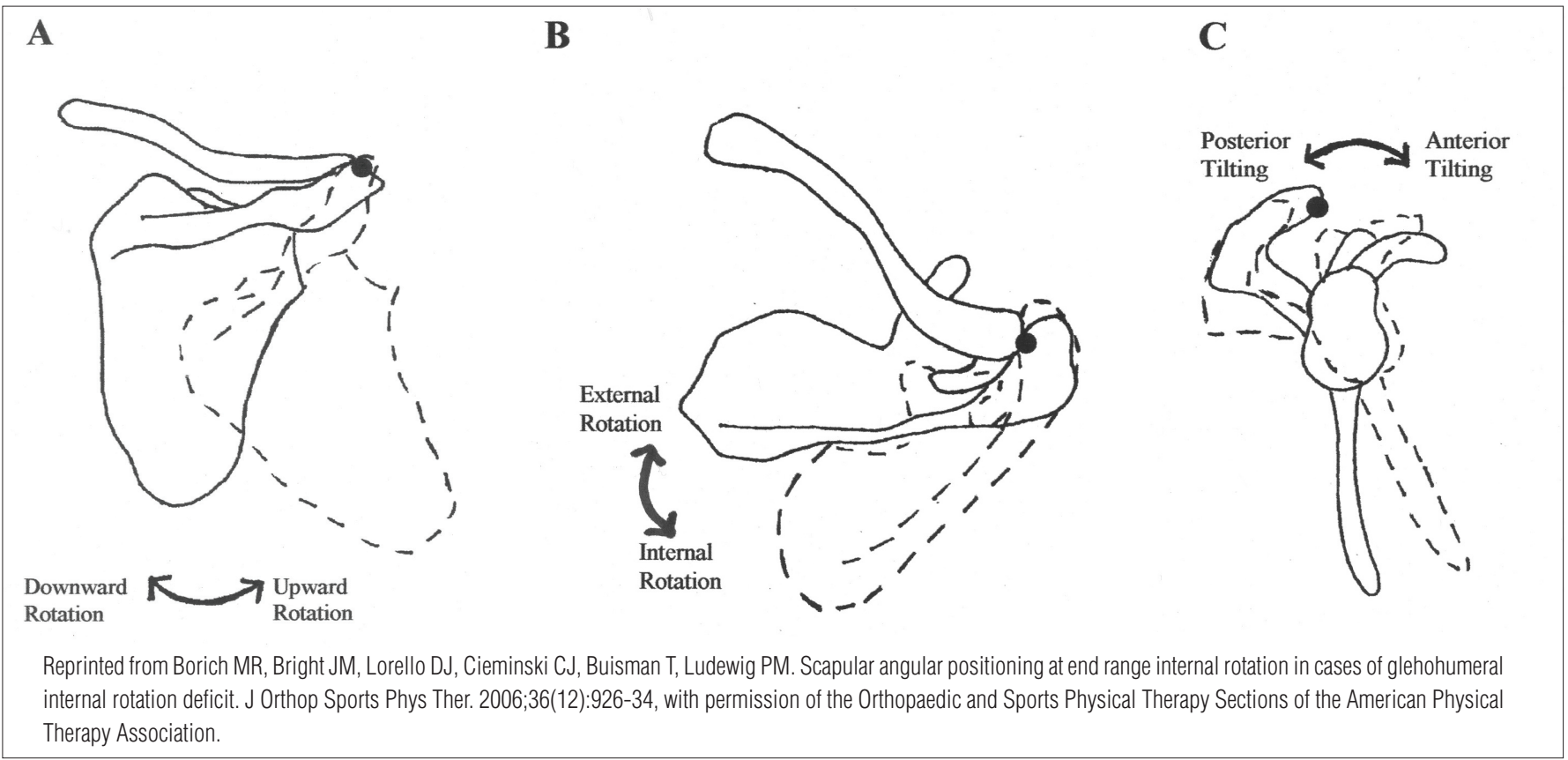

Figure 1. Scapular Motions. A) Upward/downward rotation about an axis perpendicular to the plane of the scapula; B) Internal/external rotation about a superiorly directed axis; and C) Anterior/posterior tilting about a laterally directed axis. 
clavicular elevation ${ }^{7,12,13,26}$ and retraction ${ }^{13}$, and increased anterior and superior translations of the humeral head ${ }^{11,25}$ have also been demonstrated in subjects with shoulder impingement. McClure, Michener and Karduna ${ }^{13}$ provide a summary table of many of these findings. These altered kinematics are believed to reduce the subacromial space or approximate the tendon undersurface to the glenoid labrum, creating inadequate space for clearance of the rotator cuff tendons and other subacromial structures as the arm is elevated ${ }^{27}$. These kinematic alterations have also been associated with alterations in muscle activation or resting length of shoulder muscles ${ }^{8,26,28}$. The purpose of this manuscript is to review current knowledge of how muscle activation and force production contribute to shoulder kinematics in healthy subjects and persons with shoulder impingement.

\section{Shoulder muscle action and normal kinematics}

The contributions made by muscles to normal and abnormal shoulder motion have been studied using various approaches including study of muscle activation using electromyography (EMG) during arm motion ${ }^{8,19,29}$, cadaver studies to enhance knowledge of anatomical alignment of muscles ${ }^{30}$, study of motion in patients who have nerve injuries ${ }^{31,32}$, or biomechanical modeling to predict moment arms and muscle function ${ }^{30,33}$. All of these approaches have helped to refine our knowledge about the function of shoulder muscles. Knowledge about muscle roles and dysfunction in shoulder related pathologies is vital to provide potential guidelines for interventions aimed at improving shoulder motion and function.

\section{Scapulothoracic musculature}

In shoulder related research, some authors have studied kinematics and EMG activity simultaneously to relate the functional status of the muscle with movements of the scapula. The literature has been variable with different positioning of electrodes ${ }^{8,26,34}$, different normalization techniques ${ }^{35,36}$, and limited control of the factors confounding interpretation of EMG data such as muscle length, velocity of contraction, and type of contraction ${ }^{37}$. Despite using various approaches, there has been a general consensus regarding the functions and roles of scapular muscles during arm movements. The trapezius, and middle and lower serratus anterior have been recognized as muscles which can rotate and stabilize the scapula ${ }^{29,30,34,38,39}$. It is important to note that EMG activation of a muscle during a movement, however, does not clarify if the muscle is active in a stabilizing, translating, or rotating role without further consideration of the biomechanics of the movement and the joint complex.
Inman, Sauders and Abbott ${ }^{19}$ stated that we need coordinated activity in scapular muscles for smooth movement of the scapula during arm motions. They studied raw EMG data from various muscles ${ }^{19}$ and described trapezius and lower serratus anterior as the prime movers for scapular upward rotation. Rhomboids and levator scapulae, which are downward rotators of the scapula, show lower levels of activation, presumably to synergistically resist lateral translation forces of the serratus anterior acting on the scapula. In general, scapulothoracic muscles must not only produce upward rotation during arm elevation, but also act to resist against the downward rotation torques believed produced by the reverse action of the glenohumeral muscles (deltoid and rotator cuff) acting on the scapula ${ }^{38}$.

Understanding of the role of the trapezius during shoulder motion has been refined by the work of Johnson et al. ${ }^{30}$. These authors calculated the anatomical line of action of the component fibers $^{30}$, and considered these lines of action in combination with the changing scapulothoracic axis of rotation. The middle and lower trapezius, which insert on the spine of the scapula from the acromion process to its root, are ideally suited for scapular stabilization and external rotation $^{30}$. This is because the instantaneous center of rotation of the scapula on the thorax has been found to move from the root of the spine towards the AC joint, nearly along the line of trapezius insertion ${ }^{29,38}$. The middle trapezius directed medially has only a small moment arm for upward rotation and is subsequently likely most active to offset lateral translation from the serratus anterior ${ }^{30}$. The biomechanical analysis by Johnson et al. ${ }^{30}$ also identified that the upper trapezius primary capability is elevation and retraction of the clavicle at the SC joint, as it does not attach directly to the scapula. This is consistent with data from Wiedenbauer and Mortenson ${ }^{40}$, who found that upper trapezius was most active during scapular elevation, which is produced through clavicular elevation ${ }^{30}$. Subsequently, the lower trapezius is the only component of the trapezius that can substantively upwardly rotate the scapula ${ }^{30}$. However its relative moment arm will change across the range of motion for arm elevation ${ }^{30}$.

Overall, trapezius has been found to be more active during abduction as compared to flexion ${ }^{19,40}$, consistent with less scapular internal rotation present in scapular plane abduction as compared to flexion ${ }^{15,17}$. Studies ${ }^{32,41}$ have found in patients with trapezius paralysis that the shoulder girdle "droops" and scapular downward rotation and lateral translation occur. Also, with lack of trapezius activity to stabilize the scapula, intact rhomboids and levator scapulae may be rendered inefficient to rotate the scapula ${ }^{32}$.

The middle and lower serratus anterior are aligned with a substantial mechanical advantage for scapular upward 
rotation $^{38}$, in combination with the ability to posteriorly tilt and externally rotate the scapula. Hence the middle and lower serratus anterior muscles have been most often described as the prime mover for scapular rotation during arm elevation ${ }^{30,38}$. The upper serratus anterior has been minimally investigated. ${ }^{34}$ The middle and lower serratus anterior are the only scapulothoracic muscles with the capability to both upwardly rotate and posteriorly tilt the scapula on the thorax. Their line of action will also directly approximate the scapula to the thorax, which can serve as a stable base. The functions of serratus anterior make its contribution to normal scapular kinematics during arm elevation very significant in reducing risk for scapular alterations identified with shoulder impingement symptoms, including reduced upward rotation or posterior tilting, or increased scapular internal rotation.

The pectoralis minor, with its attachments from the $3^{\text {rd }}$ to $5^{\text {th }}$ ribs to the coracoid process of the scapula can produce scapular downward rotation, internal rotation, and anterior tilt $^{28}$. These motions are opposing the desired scapular motions of upward rotation and posterior tilting during arm elevation ${ }^{15}$. Subsequently excess active or passive tension in this muscle could contribute to altered scapular kinematics during arm elevation. In a study comparing a group of healthy subjects with a short resting length of the pectoralis minor to a group with a long resting length, significant reductions in posterior tilting and increases in scapular internal rotation were found during arm elevation ${ }^{28}$. This supports the hypothesized potential for a tight pectoralis minor to alter normal scapular kinematics in directions presumed detrimental with regard to shoulder impingement risk ${ }^{28}$.

\section{Glenohumeral musculature}

At the glenohumeral joint, the deltoid is the prime mover of the arm into humeral elevation, assisted by the supraspinatus as an accessory elevator ${ }^{19,42}$. The rotator cuff also plays a critical role in stabilizing the glenohumeral joint against excessive humeral head translations through the medially directed compression of the humeral head into the glenoid and glenoid labrum ${ }^{43}$. The subscapularis, infraspinatus and teres minor also have an inferior directed line of action, which allows activation of these muscles to offset the superior translation component of deltoid muscle action ${ }^{43}$. This is likely especially important early in the range when the force vector of deltoid is primarily superiorly directed. Subsequently, a proper balance of forces between the inferiorly directed cuff muscles and the deltoid, results in very little (1 to $2 \mathrm{~mm}$ ) superior translation of the humeral head during elevation of the arm. In addition, the infraspinatus and teres minor produce the humeral external rotation that occurs during normal arm elevation.

\section{Changes in Shoulder Muscle Activity with Shoulder Impingement}

\section{Abnormal Scapulothoracic Muscle Activation}

Peat and Grahame ${ }^{44}$ investigated trapezius, middle and lower serratus anterior, and deltoid EMG in people with and without shoulder pathology. They found that upper trapezius showed increased activity during arm elevation and lowering (between 40 to 100 degrees of arm elevation), and serratus anterior showed decreased activity at some humeral elevation angles (between 70 to 100 degrees) in patients as compared to healthy controls.

Scovozzo et al. ${ }^{45}$ used EMG to evaluate muscle activity during swimming motions in athletes with and without shoulder pain. Their study revealed a significant decrease in the activity of the anterior and middle fibers of the deltoid, subscapularis and middle and lower serratus anterior during different phases of the swimming motion. The authors propose that the muscles showed decreased activity either due to shoulder pain or that pain caused the athletes to use alternative motions and muscles during the action of swimming. It can be concluded that people with pain used a different motor program for the task using different muscle activation patterns.

Ludewig and $\mathrm{Cook}^{8}$ reported significantly decreased lower serratus anterior activation from 31 to 120 degrees of humeral elevation in the scapular plane in construction workers with a clinical diagnosis of shoulder impingement as compared to asymptomatic workers. Increased upper and lower trapezius activation was also found from 61 to 120 degrees under loaded conditions ${ }^{8}$. Lin et al. ${ }^{26}$ reported similar results while investigating functional tasks in a vaguely defined symptomatic group who showed an increase in upper trapezius activity and decrease in lower serratus anterior activity as compared to healthy controls. Other authors have surmised that middle and lower serratus anterior weakness or reduced activity may contribute to impingement syndrome in the shoulder ${ }^{46,47}$. Thus improvement in the function of the middle and lower serratus muscles through rehabilitation may help alleviate pain and dysfunction ${ }^{46,47}$.

An increase in upper trapezius activity in subjects with pathology has also been a consistent finding across studies ${ }^{8,26,44}$. This finding may be associated with the increase in clavicular elevation or scapular elevation found in several clinical and kinematic studies ${ }^{7,13,48}$. This increased upper trapezius activation may be viewed as a common compensatory strategy used by people with shoulder pain and pathology to elevate their arm. However, the subsequent increase in clavicle elevation at the SC joint that may be produced by increased upper trapezius activity ${ }^{30}$ will result in scapular anterior tilt, offsetting the scapular posterior tilt produced at the $\mathrm{AC}$ joint ${ }^{20}$. This may 
reduce the overall posterior tilt of the scapula on the thorax and may be viewed as a potential mechanism to either cause or aggravate impingement symptoms.

\section{Scapulothoracic muscle timing}

Thus across studies, changes in the activity of the scapular muscles, especially trapezius and middle and lower serratus anterior, have been associated with various shoulder related pathologies including shoulder impingement. Motor control alterations have been proposed as a cause for these muscle activity changes ${ }^{18,49}$. These motor control changes may include a delayed activation or deactivation of the muscle such that it fails to be recruited on time, and/or fails to maintain its required level of activation throughout the range of motion. Conversely excess activation of the muscles may occur.

Two studies have looked at the relationship of scapular muscle latencies during elevation of the arm in persons with shoulder impingement and controls ${ }^{50,51}$. Both studies had a different methodological approach and use of small sample sizes such that statistical power is often inadequate. One of the earliest works was done by Wadsworth and Bullock-Saxton ${ }^{50}$ in swimmers, where they compared the latency of the upper fibers of trapezius, lower fibers of trapezius, and middle and lower serratus anterior. These latencies were compared between the painful and contralateral shoulders in 9 swimmers with symptoms of shoulder impingement and 9 healthy controls matched for height, weight, training mileage and skilled hand preference. The EMG from the muscles was recorded while elevating the arm in the scapular plane at a speed of 40 degrees per second. The onset time was defined as when the muscles reached $5 \%$ of their maximum amplitude from the moment the motion was detected by an inclinometer attached to the arm. Muscle latency of middle and lower serratus anterior appeared delayed bilaterally in subjects with impingement and there was an apparent increased variability associated with muscle latencies in subjects with shoulder pain, as demonstrated by larger within and between subject variance. However, no group latency differences reached statistical significance. The study may have failed to find group differences due to inadequate power owing to the small sample size. Also, the study does not provide information about the relative latencies of the scapular muscles as compared to the deltoid.

Another recent study ${ }^{51}$ compared two groups with and without shoulder impingement for muscle latency of trapezius and middle and lower serratus anterior bilaterally during scapular plane elevation of the arm. The study did not find significant group differences which can be also attributed to low sample size $(n=10)$ and low power. Nevertheless, they report that side to side differences were observed for the impingement group only, demonstrating delayed activation on the affected side. The speed of motion which can be considered as a confounding factor for EMG analysis of latency was not controlled in the study and subjects moved at a self determined comfortable speed. The authors have stated that the results obtained by their study for controls are similar to those obtained by Wadsworth and Bullock-Saxton ${ }^{50}$. However, Moraes, Faria and Teixeira-Salmela ${ }^{51}$ have calculated the latency from the moment the subjects were shown a light source whereas Wadsworth and Bullock-Saxton ${ }^{50}$ had used the moment of initiation of arm movement. It is known that the visual reaction time is approximately $150 \mathrm{~ms}$ to $200 \mathrm{~ms}^{52}$ and therefore direct comparisons to different reference actions are more difficult to make. Even when adjustments are made for the visual reaction time, the latency values obtained by Wadsworth and Bullock-Saxton ${ }^{50}$ are considerably smaller than those obtained by Moraes, Faria and Teixeira-Salmela ${ }^{51}$.

The latency of muscles has also been investigated in response to sudden perturbations which probably are more indicative of a reflexive protective mechanism rather than any programmed motor control strategy. Cools et al..$^{53}$ studied relative latency of the three parts of trapezius as compared to middle deltoid during a sudden adduction perturbation, in other words a sudden drop of the arm, from a 90 degree elevated position in athletes with and without shoulder impingement. Muscle latency was defined as the time needed for the muscle to reach $10 \%$ of its maximum voluntary contraction from the time movement was detected. A sample of 39 patients and 30 controls was investigated. The study compared the relative latency of the trapezius muscle between the two groups and between the injured side and non-injured side of patients and the dominant and nondominant side of the controls. The study found significant group differences with a delayed middle and lower trapezius onset in subjects with impingement as compared to controls. Also, the relative activation of lower trapezius was significantly delayed on the injured side as compared to the non-injured side in subjects with impingement.

\section{Rotator cuff muscle activation}

Reddy et al ${ }^{54}$ compared the muscle activity of the middle deltoid and rotator cuff muscles during abduction in the scapular plane in subjects with shoulder impingement and healthy subjects. Overall, the impingement group demonstrated decreased activity of the deltoid and rotator cuff muscles, and this was most pronounced in the early arcs of motion. In the impingement group, the infraspinatus, subscapularis and middle deltoid muscles demonstrated decreased activity during the 30 to 60 degree arc. During the 60 to 90 degree arc, the infraspinatus was the only muscle with 
decreased activity. None of the comparisons in the 90 to 120 degree arc showed differences. The authors ${ }^{54}$ suggest that this reduced rotator cuff activation may relate to inadequate humeral head depression (or excess superior translation of the humerus) during the critical first portion of elevation of the arm in people with shoulder impingement.

Myers et al. ${ }^{55}$ measured rotator cuff (supraspinatus, infraspinatus and subscapularis) coactivation and middle deltoid muscle activation during elevation of the arm in subjects with shoulder impingement and control subjects. Subjects with impingement showed significantly decreased rotator cuff coactivation (subscapularis with infraspinatus or supraspinatus) and increased middle deltoid activation from 0 to 30 degrees of elevation; decreased coactivation of the rotator cuff (supraspinatus with infraspinatus) from 30 to 60 degrees of elevation; and higher coactivation of the rotator cuff (infraspinatus with subscapularis or supraspinatus) from 90 to 120 degrees of elevation of the arm as compared to the control group. These results suggest that subjects with shoulder impingement exhibit decreased rotator cuff coactivation and increased deltoid activation at the initiation of humeral elevation, in general agreement with the findings of Reddy and colleagues ${ }^{54}$. As noted above, this reduced rotator cuff activation may contribute to further shoulder impingement with excess superior translation of the humeral head.

\section{Summary and clinical considerations}

Based on the currently available literature, some important summary information can be assimilated (Table 1) for consideration in the care of patients presenting with shoulder impingement syndrome. There is general consensus that the middle and lower serratus anterior is the prime mover of the scapula on the thora $\mathrm{x}^{30,38}$. Based on its alignment, this muscle can also upwardly rotate, posteriorly tilt and externally rotate the scapula at the
AC joint. There is also evidence of reduced activation of this muscle in persons with shoulder impingement ${ }^{8,26}$. Subsequently, exercises to increase the strength or relative activation of the middle and lower serratus anterior are important to consider in the rehabilitation of shoulder impingement. This is particularly true if a patient presents with a lack of scapular posterior tilting during arm elevation, as noted by prominence of the scapular inferior angle. Emphasis on middle and lower serratus anterior exercise is also important to consider for impingement patients presenting with reduced scapular upward rotation.

The function of the trapezius during arm elevation is now known to be different for the different component portions of the muscle (upper, middle, and lower) ${ }^{30}$. The upper trapezius functions to elevate and retract the clavicle. Very little clavicular elevation normally occurs during arm elevation in healthy subjects ${ }^{15,17,21}$. Excess clavicular elevation is also mechanically linked to the undesired motion of scapular anterior tilting ${ }^{20}$. Excess upper trapezius activation ${ }^{8,26}$ and excess clavicular elevation and retraction ${ }^{13}$ have been identified in subjects with impingement. Thus exercises to increase the strength or relative activation of the upper trapezius may be counterproductive in most patients with shoulder impingement symptoms. The exception may be those presenting with depressed or protracted clavicular positions.

The middle trapezius plays primarily a stabilizing role in controlling scapular position. Delayed activation of this muscle in response to a perturbation of dropping the arm has been identified in impingement patients ${ }^{53}$. Thus use of exercises for this muscle in rehabilitation programs may be most appropriate for patients with excess scapular internal rotation presenting as prominence of the medial or vertebral scapular border. The lower trapezius appears to act both as a medial stabilizer similar to the middle trapezius, as well as an accessory scapular upward rotator assisting the serratus anterior ${ }^{30}$. Delayed activation in impingement patients in response to dropping the arm

Table 1: Alterations in muscle activity/latency observed in subjects with shoulder impingement or shoulder pain consistent with impingement.

\begin{tabular}{|c|c|c|}
\hline Alterations & Study & Sample \\
\hline \multirow[t]{3}{*}{ Increased upper trapezius activity } & Peat and Grahame ${ }^{44}$ & $\begin{array}{l}30 \text { healthy, } 18 \text { with shoulder pain ( } 7 \text { impingement), } \\
39-70 \text { years old }\end{array}$ \\
\hline & Ludewig and Cook & $\begin{array}{l}26 \text { healthy, } 26 \text { with impingement, } 20-71 \text { years old, } \\
\text { males only, overhead construction workers }\end{array}$ \\
\hline & Lin et al. ${ }^{26}$ & $\begin{array}{l}25 \text { healthy, } 21 \text { with shoulder dysfunction, } \\
27-82 \text { years old, males only }\end{array}$ \\
\hline \multirow[t]{3}{*}{ Reduced middle to lower serratus anterior activity } & Peat and Grahame ${ }^{44}$ & As above \\
\hline & Ludewig and Cook ${ }^{8}$ & As above \\
\hline & Lin et al. ${ }^{26}$ & As above \\
\hline \multirow[t]{2}{*}{ Reduced rotator cuff activity/ coactivation } & Reddy et al..$^{54}$ & 15 healthy, 15 with impingement \\
\hline & Myers et al..$^{55}$ & 10 healthy, 10 with impingement \\
\hline $\begin{array}{l}\text { Delayed middle and lower trapezius relative latency } \\
\text { to sudden perturbation }\end{array}$ & Cools et al. ${ }^{53}$ & $\begin{array}{l}30 \text { healthy, } 39 \text { with impingement, } 16-35 \text { years old, } \\
\text { overhand athletes }\end{array}$ \\
\hline $\begin{array}{l}\text { Delayed activation and increased variability in ser- } \\
\text { ratus anterior latency }\end{array}$ & Wadsworth and Bullock-Saxton ${ }^{50}$ & $\begin{array}{l}9 \text { healthy, } 9 \text { with impingement, } 40-66 \text { years old, } \\
\text { swimmers }\end{array}$ \\
\hline
\end{tabular}


has also been noted for the lower trapezius ${ }^{53}$. Subsequently, patients presenting either with excess scapular internal rotation or reduced scapular upward rotation may benefit from incorporation of lower trapezius exercises into their rehabilitation.

Very little has been investigated regarding the involvement of rhomboids and levator scapulae in subjects with impingement syndrome. Clinicians should be cautious in prescribing strengthening exercises for these muscles in patients presenting with prominence of the medial scapular border as these muscles also act as downward rotators of the scapula.

The pectoralis minor as a scapular downward rotator, anterior tilter, and internal rotator is essentially an antagonist to the necessary scapulothoracic motions during elevation of the arm. A reduced resting length of this muscle has been shown to result in increased scapular internal rotation and reduced posterior tilting as the arm is raised over head ${ }^{28}$. Subsequently, clinically assessing the resting length of this muscle, as described by Borstad ${ }^{56}$, is recommended when evaluating patients with shoulder impingement. Impingement patients with tightness in the pectoralis minor may benefit from stretching to reduce the resistance to production of normal scapular rotations.

The rotator cuff plays a role not only in producing glenohumeral internal and external rotation, but more critically in stabilizing the humeral head on the glenoid, and preventing excess superior translation of the humeral head that would otherwise result from deltoid activation ${ }^{43}$. Increased superior translation of the humeral head ${ }^{25}$ and decreased activation of the rotator cuff early in the range of arm elevation ${ }^{54,55}$ have been demonstrated in subjects with impingement as compared to healthy controls. Incorporating rotator cuff exercises into the rehabilitation program for impingement patients is common practice. Rotator cuff strength is critical to regain prior to working on active elevation of the humerus, to ensure adequate strength of the rotator cuff and thus ensure stabilization of the humeral head prior to elevating the humerus. The clinician is well advised to ensure the patient has adequate scapular control when performing these exercises, and to ensure patients do not experience increased symptoms with rotator cuff exercises early in the rehabilitation program.

\section{Conclusion $: \because$}

Despite nearly 70 years of research data on shoulder function and dysfunction, there is still much yet to understand regarding the complex interactions of multiple muscles to produce the coordinated 3-D motion of the shoulder complex. The quantitative capabilities of the muscles in 3-D, across varying shoulder positions, and in reverse action, require further investigation. In addition, the motor control of coordinated shoulder function remains minimally investigated. Several clinical trials have demonstrated significant positive effects of shoulder exercises in alleviating shoulder impingement symptoms ${ }^{57-63}$. Continued refinement of shoulder impingement exercise approaches holds promise for further gains in rehabilitation effectiveness for these patients.

\section{Acknowledgements : :}

This work was supported by NIH grant \# K01HD042491 from the National Institute of Child Health and Human Development. The content is solely the responsibility of the authors and does not necessarily represent the views of the National Institute of Child Health and Human Development or the National Institutes of Health. This work was also supported by the Brazilian agency, Conselho Nacional de Desenvolvimento Científico e Tecnológico (CNPq), through a fellowship for Paula R Camargo.

\section{References $: \because$.}

1. Neer CS. Anterior acromioplasty for the chronic impingement syndrome in the shoulder: a preliminary report. J Bone Joint Surg Am. 1972;54(1):41-50.

2. van der Windt DA, Koes BW, de Jong BA, Bouter LM. Shoulder disorders in general practice: Incidence, patient characteristics, and management. Ann Rheum Dis. 1995;54(12):959-64.

3. Soslowsky LJ, Thomopoulos S, Esmail A, Flanagan CL, lannotti JP, Williamson JD 3rd, et al. Rotator cuff tendinosis in an animal model: Role of extrinsic and overuse factors. Ann Biomed Eng. 2002;30(8):1057-63.

4. Walch G, Boileau P, Noel E, Donell ST. Impingement of the deep surface of the supraspinatus tendon on the posterosuperior glenoid rim: An arthroscopic study. J Bone Joint Surg. 1992;9:36-46.
5. Pappas GP, Blemker SS, Beaulieu CF, McAdams TR, Whalen ST, Gold $\mathrm{GE}$. In vivo anatomy of the neer and hawkins sign positions for shoulder impingement. J Shoulder Elbow Surg. 2006;15(1):40-9.

6. Jobe FW, Pink M. The athlete's shoulder. J Hand Ther. 1994;7(2):107-10.

7. Lukaseiwicz AC, McClure P, Michener L, Pratt N, Sennett B. Comparison of 3-dimensional scapular position and orientation between subjects with and without shoulder impingement. J Orthop Sports Phys Ther. 1999;29(10):574-83.

8. Ludewig PM, Cook TM. Alterations in shoulder kinematics and associated muscle activity in people with symptoms of shoulder impingement. Phys Ther. 2000;80(3):276-91. 
9. Endo K, Ikata T, Katoh S, Takeda Y. Radiographic assessment of scapular rotational tilt in chronic shoulder impingement syndrome. J Orthop Sci. 2001;6(1):3-10.

10. Hebert LJ, MoffetH, McFadyen BJ, Dionne CE. Scapular behavior in shoulder impingement syndrome. Arch Phys Med Rehabil. 2002;83(1):60-9.

11. Ludewig PM, Cook TM. Translations of the humerus in persons with shoulder impingement symptoms. J Orthop Sports Phys Ther. 2002;32(6):248-59.

12. Laudner KG, Myers JB, Pasquale MR, Bradley JP, Lephart SM. Scapular dysfunction in throwers with pathologic internal impingement. J Orthop Sports Phys Ther. 2006;36(7):485-94.

13. McClure PW, Michener LA, Karduna AR. Shoulder function and 3-dimensional scapular kinematics in people with and without shoulder impingement syndrome. Phys Ther. 2006;86(8):1075-90.

14. Ludewig PM, Cook TM, Nawoczenski DA. Three-dimensional scapular orientation and muscle activity at selected positions of humeral elevation. J Orthop Sports Phys Ther. 1996;24(2):57-65.

15. McClure PW, Michener LA, Sennett BJ, Karduna AR. Direct 3-dimensional measurement of scapular kinematics during dynamic movements in vivo. J Shoulder Elbow Surg. 2001;10(3):269-77.

16. Borstad JD, Ludewig PM. Comparison of scapular kinematics between elevation and lowering of the arm in the scapular plane. Clin Biomech. 2002;17(9-10):650-9.

17. Ludewig PM, Phadke V, Braman JP, Hassett DR, Cieminski CJ, LaPrade RF. Motion of the shoulder complex during multiplanar humeral elevation. J Bone Joint Surg Am. 2009;91(2):378-89.

18. Kibler WB, McMullen J. Scapular dyskinesis and its relation to shoulder pain. J Am Acad Orthop Surg. 2003;11(2):142-51.

19. Inman VT, Saunders JB, Abbott LC. Observations on the function of the shoulder joint. J Bone Joint Surg. 1944;26A:1-30.

20. Teece RM, Lunden JB, Lloyd AS, Kaiser AP, Cieminski CJ, Ludewig PM. Three-dimensional acromioclavicular joint motions during elevation of the arm. J Orthop Sports Phys Ther. 2008;38(4):181-90.

21. Ludewig PM, Behrens SA, Meyer SM, Spoden SM, Wilson LA. Threedimensional clavicular motion during arm elevation: Reliability and descriptive data. J Orthop Sports Phys Ther. 2004;34(3):140-9.

22. Sahara W, Sugamoto K, Murai M, Yoshikawa H. Three-dimensional clavicular and acromioclavicular rotations during arm abduction using vertically open MRI. J Orthop Res. 2007;25(9):1243-9.

23. An KN, Browne AO, Korinek S, Tanaka S, Morrey BF. Three-dimensional kinematics of glenohumeral elevation. J Orthop Res. 1991;9:143-9.

24. Warner JJ, Micheli LJ, Arslanian LE, Kennedy J, Kennedy R. Scapulothoracic motion in normal shoulders and shoulders with glenohumeral instability and impingement syndrome: A study using moire topographic analysis. Clin Orthop Rel Res. 1992;285:191-9.

25. Deutsch A, Altchek D, Schwartz E, Otis JC, Warren RF. Radiologic measurement of superior displacement of humeral head in impingement syndrome. J Shoulder Elbow Surg. 1996;5(3):186-93.
26. Lin JJ, Hanten WP, Olson SL, Roddey TS, Soto-quijano DA, Lim HK, et al. Functional activity characteristics of individuals with shoulder dysfunctions. J Electromyogr Kinesiol. 2005;15(6):576-86.

27. Graichen $H$, Bonel $H$, Stammberger $T$, Haubner M, Rohrer $H$, Englmeier $\mathrm{KH}$, et al. Three-dimensional analysis of the width of the subacromial space in healthy subjects and patients with impingement syndrome. Am J Roentgenol. 1999;172(4):1081-6.

28. Borstad JD, Ludewig PM. The effect of long versus short pectoralis minor resting length on scapular kinematics in healthy individuals. J Orthop Sports Phys Ther. 2005;35(4):227-38.

29. Bagg SD, ForrestWJ. Electromyographic study of the scapular rotators during arm abduction in the scapular plane. Am J Phys Med. 1986;65(3):111-24.

30. Johnson G, Bogduk N, Nowitzke A, House D. Anatomy and actions of the trapezius muscle. Clin Biomech. 1994;9:44-50.

31. Brunnstrom S. Muscle testing around the shoulder girdle: A study of the function of shoulder-blade fixators in seventeen cases of shoulder paralysis. J Bone Joint Surg. 1941;23A:263-72.

32. Wiater JM, Bigliani LU. Spinal accessory nerve injury. Clin Orthop Relat Res. 1999;(368):5-16.

33. Poppen NK, Walker PS. Forces at the glenohumeral joint in abduction. Clin Orthop Relat Res. 1978;135:165-70.

34. Ekstrom RA, Bifulco KM, Lopau CJ, Andersen CF, Gough JR. Comparing the function of the upper and lower parts of the serratus anterior muscle using surface electromyography. J Orthop Sports Phys Ther. 2004;34(5):235-43.

35. McLean L, Chislett M, Keith M, Murphy M, Walton P. The effect of head position, electrode site, movement and smoothing window in the determination of a reliable maximum voluntary activation of the upper trapezius muscle. J Electromyogr Kinesiol. 2003;13(2):169-80.

36. Ekstrom RA, Soderberg GL, Donatelli RA. Normalization procedures using maximum voluntary isometric contractions for the serratus anterior and trapezius muscles during surface EMG analysis. J Electromyogr Kinesiol. 2005;15(4):418-28.

37. Heckathorne CW, Childress DS. Relationships of the surface electromyogram to the force, length, velocity, and contraction rate of the cineplastic human biceps. Am J Phys Med. 1981;60(1):1-19.

38. Dvir Z, Berme N. The shoulder complex in elevation of the arm: A mechanism approach. J Biomech. 1978;11(5):219-25.

39. Johnson GR, Pandyan AD. The activity in the three regions of the trapezius under controlled loading conditions--an experimental and modelling study. Clin Biomech. 2005;20(2):155-61.

40. Wiedenbauer MM, Mortensen OA. An electromyographic study of the trapezius muscle. Am J Phys Med. 1952;31(5):363-72.

41. Chan PK, Hems TE. Clinical signs of accessory nerve palsy. J Trauma. 2006;60(5):1142-4.

42. Sharkey NA, Marder RA, Hanson PB. The entire rotator cuff contributes to elevation of the arm. J Orthop Res. 1994;12(5):699-708. 
43. Sharkey NA, Marder RA. The rotator cuff opposes superior translation of the humeral head. Am J Sports Med. 1995;23(3):270-5.

44. Peat M, Grahame RE. Electromyographic analysis of soft tissue lesions affecting shoulder function. Am J Phys Med. 1977;56(5):223-40.

45. Scovazzo ML, Browne A, Pink M, Jobe FW, Kerrigan J. The painful shoulder during freestyle swimming: An electromyographic cinematographic analysis of twelve muscles. Am J Sports Med. 1991;19(6):577-82.

46. Nuber GW, Jobe FW, Perry J, Moynes DR, Antonelli D. Fine wire electromyography analysis of muscles of the shoulder during swimming. Am J Sports Med. 1986;14(1):7-11.

47. Schmitt L, Snyder-Mackler L. Role of scapular stabilizers in etiology and treatment of impingement syndrome. J Orthop Sports Phys Ther. 1999;29(1):31-8.

48. Burkhart SS, Morgan CD, Kibler WB. The disabled throwing shoulder: Spectrum of pathology part III: The SICK scapula, scapular dyskinesis, the kinetic chain, and rehabilitation. Arthroscopy. 2003;19(6):641-61.

49. Davies GJ, Dickoff-Hoffman S. Neuromuscular testing and rehabilitation of the shoulder complex. J Orthop Sports Phys Ther. 1993;18(2):449-58.

50. Wadsworth DJ, Bullock-Saxton JE. Recruitment patterns of the scapular rotator muscles in freestyle swimmers with subacromial impingement. Int J Sports Med. 1997;18(8):618-24.

51. Moraes GF, Faria CD, Teixeira-Salmela LF. Scapular muscle recruitment patterns and isokinetic strength ratios of the shoulder rotator muscles in individuals with and without impingement syndrome. J Shoulder Elbow Surg. 2008;17(1 Suppl):S48-53.

52. Schmidt R, Lee T. Motor Control and Learning: A Behavioral Emphasis. 4th ed. Champaign, IL: Human Kinetics; 2005.

53. Cools AM, Witvrouw EE, Declercq GA, Danneels LA, Cambier DC. Scapular muscle recruitment patterns: Trapezius muscle latency with and without impingement symptoms. Am J Sports Med. 2003;31(4):542-9.
54. Reddy AS, Mohr KJ, Pink MM, Jobe FW. Electromyographic analysis of the deltoid and rotator cuff muscles in persons with subacromial impingement. J Shoulder Elbow Surg. 2000;9(6):519-23.

55. Myers JB, Hwang JH, Pasquale MR, Blackburn JT, Lephart SM. Rotator cuff coactivation ratios in participants with subacromial impingement syndrome. J Sci Med Sport. 2008; doi:10.1016/j.jsams.2008.06.003.

56. Borstad JD. Measurement of pectoralis minor muscle length: Validation and clinical application. J Orthop Sports Phys Ther. 2008;38(4):169-74.

57. Brox JI, Gjengedal E, Uppheim G, Bohmer AS, Brevik JI, Ljunggren AE, et al. Arthroscopic surgery versus supervised exercises in patients with rotator cuff disease (stage II impingement syndrome): J Shoulder Elbow Surg. 1999;8(2):102-11.

58. Bang MD, Deyle GD. Comparison of supervised exercise with and without manual physical therapy for patients with shoulder impingement syndrome. J Orthop Sports Phys Ther. 2000;30(3):126-37.

59. Ludewig PM, Borstad JD. Effects of a home exercise programme on shoulder pain and functional status in construction workers. Occup Environ Med. 2003;60(11):841-9.

60. McClure PW, Bialker J, Neff N, Williams G, Karduna A. Shoulder function and 3-dimensional kinematics in people with shoulder impingement syndrome before and after a 6-week exercise program. Phys Ther. 2004;84(9):832-48.

61. Michener LA, Walsworth MK, Burnet EN. Effectiveness of rehabilitation for patients with subacromial impingement syndrome: A systematic review. J Hand Ther. 2004;17(2):152-64.

62. Jonsson $P$, Wahlstrom $P$, Ohberg $L$, Alfredson $H$. Eccentric training in chronic painful impingement syndrome of the shoulder: Results of a pilot study. Knee Surg Sports Traumatol Arthrosc. 2006;14(1):76-81.

63. Camargo PR, Haik MN, Ludewig PM, Filho RB, Mattiello-Rosa SMG, Salvini TF. Effects of strengthening and stretching exercises applied during working hours on pain and physical impairment in workers with subacromial impingement syndrome. Physiother Theory Pract. 2009; in press. 